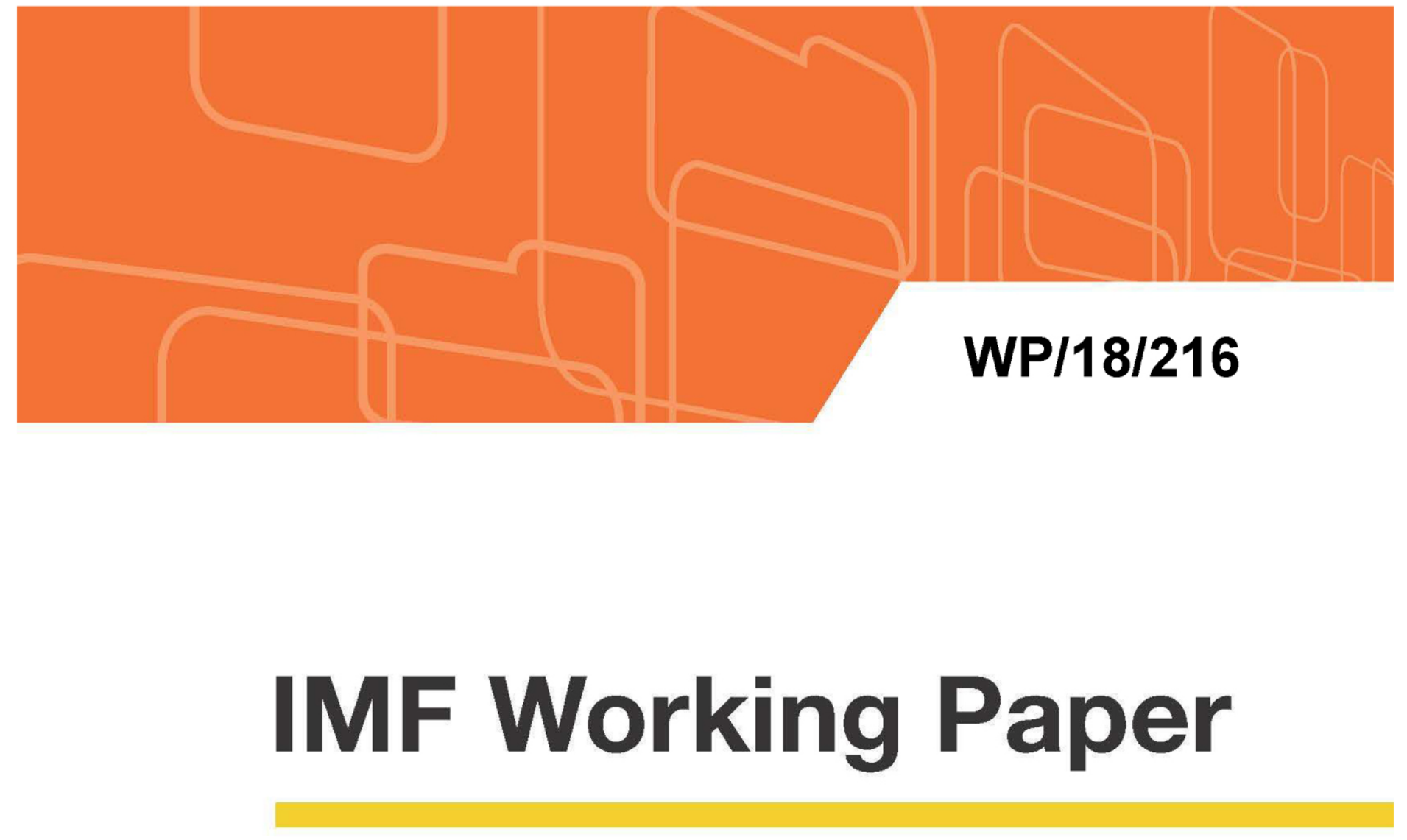

\title{
China's Capacity Reduction Reform and Its Impact on Producer Prices
}

\author{
by Linxi Chen, Ding Ding and Rui C. Mano
}

IMF Working Papers describe research in progress by the author(s) and are published to elicit comments and to encourage debate. The views expressed in IMF Working Papers are those of the author(s) and do not necessarily represent the views of the IMF, its Executive Board, or IMF management.

$$
\text { I N T E R N A T I O N A L M O N E T A R Y F U N D }
$$




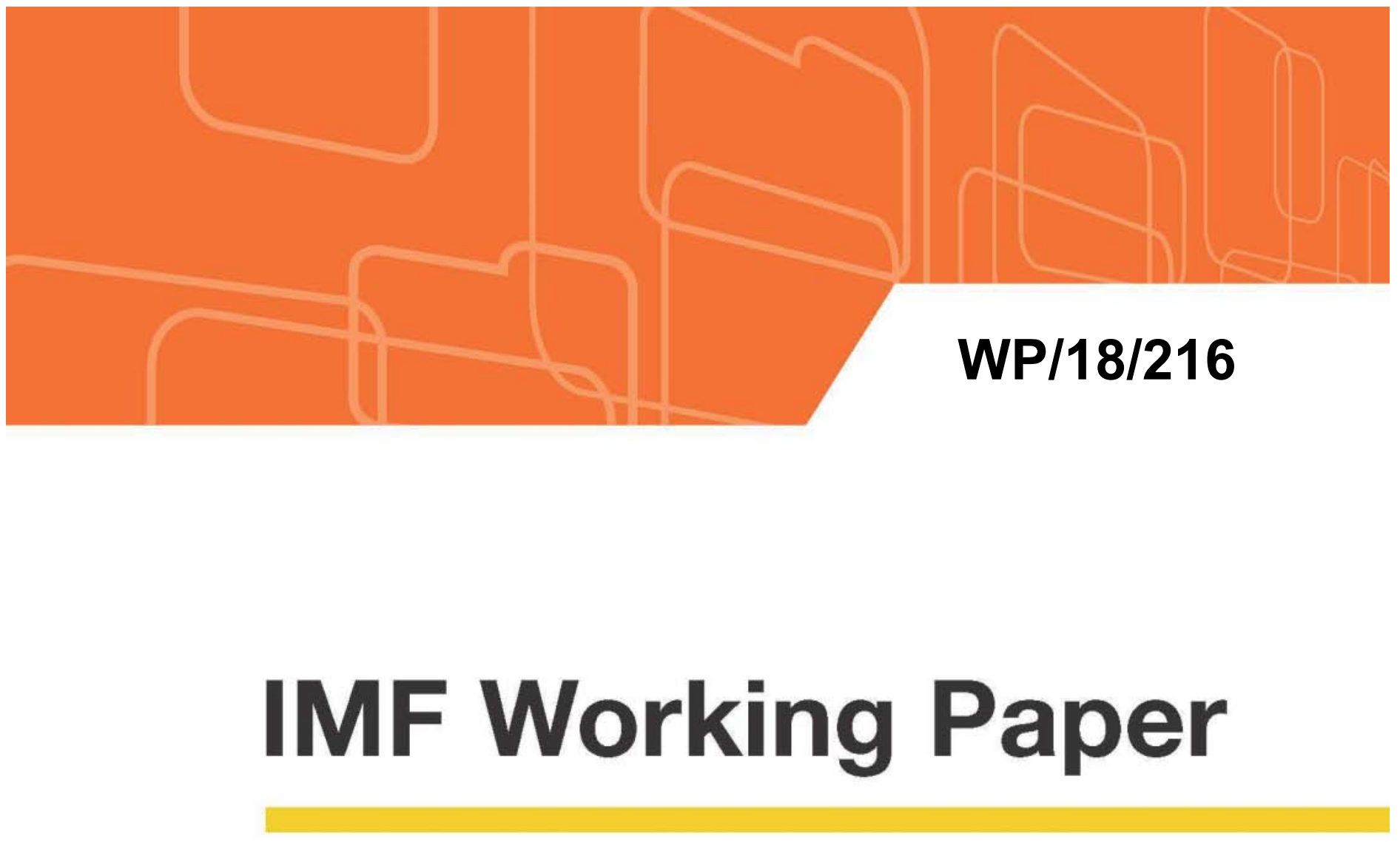

\title{
China's Capacity Reduction Reform and Its Impact on Producer Prices
}

\author{
by Linxi Chen, Ding Ding and Rui C. Mano
}

IMF Working Papers describe research in progress by the author(s) and are published to elicit comments and to encourage debate. The views expressed in IMF Working Papers are those of the author(s) and do not necessarily represent the views of the IMF, its Executive Board, or IMF management.

$$
\text { I N TER N A T I O N A L M O N E T A R Y F U N D }
$$




\title{
IMF Working Paper
}

Asia and Pacific Department

\section{China's Capacity Reduction Reform and Its Impact on Producer \\ Prices Prepared by Linxi Chen, Ding Ding and Rui C. Mano ${ }^{1}$}

Authorized for distribution by James Daniel

September 2018

\section{IMF Working Papers describe research in progress by the author(s) and are published to elicit comments and to encourage debate. The views expressed in IMF Working Papers are those of the author(s) and do not necessarily represent the views of the IMF, its Executive Board, or IMF management.}

\begin{abstract}
In late 2015, the Chinese authorities launched a policy to reduce capacity in the coal and steel industries under the wider effort of Supply-Side Structural Reforms. Around the same time, producer price inflation in China started to pick up strongly after being trapped in negative territory for more than fifty consecutive months. So what is behind this strong reflation-capacity cuts in coal and steel, or a strengthening of aggregate demand? Our empirical analyses indicate that a pickup in aggregate demand, possibly due to the government's stimulus package in 2015-16, was the more important driver. Capacity cuts played a role in propping up coal and steel prices, explaining at most 40 percent of their price increase.

JEL Classification Numbers: E31, C22, E65

Keywords: China, capacity reduction, supply-side structural reforms, producer price index Author’s E-Mail Address: linxi.chen@duke.edu; dding@,1mf.org; rmano@imf.org

\footnotetext{
${ }^{1}$ Ding Ding and Rui C. Mano work for the International Monetary Fund. Linxi Chen is from Duke University. We would like to thank James Daniel, Sonali Jain-Chandra, Markus Rodlauer and participants at the IMF Asia and Pacific Department (APD) seminar for helpful comments, and Jacqueline Jiayi Zhang for excellent research assistance. The usual disclaimer applies.
} 


\section{INTRODUCTION}

1. The Chinese economy is undergoing a transition with policymakers putting increasing emphasis on the quality rather than the quantity of growth. Years of rapid growth, driven by investment and credit expansion, led to significant accumulation of structural imbalances in the economy, including a large debt overhang, risks in the financial system, the proliferation of "zombie firms" (those that operate at a loss persistently), a rapid buildup of inventories in residential housing and excess capacity in certain industrial sectors. As the economy entered a "new normal" with the annual growth rate declining from double digits in the aftermath of the Global Financial Crisis (GFC) to 6-7 percent, the Chinese government announced in December 2015 that Supply-Side Structural Reforms (SSSR) would help "guide the economy to a new normal." The $19^{\text {th }}$ Party Congress, held in October 2017, further elevated the SSSR as a main task in the national strategy of developing a modernized economy.

2. There are five areas of focus under the SSSR: capacity reduction, housing inventory destocking, corporate deleveraging, reducing corporate costs, and improving "weak links" which contains a suite of measures aimed at industrial upgrading, infrastructure investment and etc. They are known in Chinese as the "three cuts, one reduction, and one improvement". In essence, the SSSR represents a departure from China's traditional demand-side stimulus policies to improve the quality of growth by addressing the structural imbalances in the economy. The Chinese "supply-side reforms" include a broader set of policies, including some designed to boost demand (e.g. housing destocking was partly achieved through increased support for home purchases).

3. In this paper, we focus solely on capacity reduction under the SSSR. For years, China's investment-driven growth model led to persistently strong demand for commodities and heavy-industry products, fostering substantial capital investments in the industrial sector. For example, more than a third of the 4-trillion-yuan post-GFC stimulus package was channeled to transport and power infrastructure projects, resulting in rapid capacity and production expansion in many heavy industries including steel and coal (Fan 2016). In addition, extensive government subsidies, such as cheap land and credit, discounted power costs and tax breaks, were provided to about 30 percent of industrial output and represent a major driver of China's excess capacity (Haley and Haley 2013).

4. Capacity cuts first targeted two heavy industries that experienced rapid expansion in recent years - steel and coal. From 1996 to 2010, China's steel production increased by more than six folds from around 100 million metric tons to 627 million tons, and its share in global steel production rose from 13.5 percent to 44.3 percent (Greenpeace 2017). Coal production in China grew by 3.9 percent per year in 2006-15, compared to the global growth rate of 2.5 percent. China accounted for 47 percent of global coal production in 2015 with a total production of 1.8 billion tons (BP 2017). As GDP growth started to decline in China after 2010, capacity utilization in the steel industry also contracted from 79 percent in 2010 to less than 70 percent in 2015, and that for the coal industry declined from more than 90 percent to 65 percent. Falling capacity utilization was accompanied by a sizable deterioration in 
corporate profitability and debt-servicing capacity. By end-2015, the coal and steel industries accounted for around 14 percent of corporate debt in China's industrial sector. It would take 91 years and 74 years, respectively, for the coal and ferrous metal smelting (including steel) industries to pay back total debts at their current cash flow generation levels, compared to the industrial sector average of under 10 years (EIU 2017).

5. China's excess industrial capacity

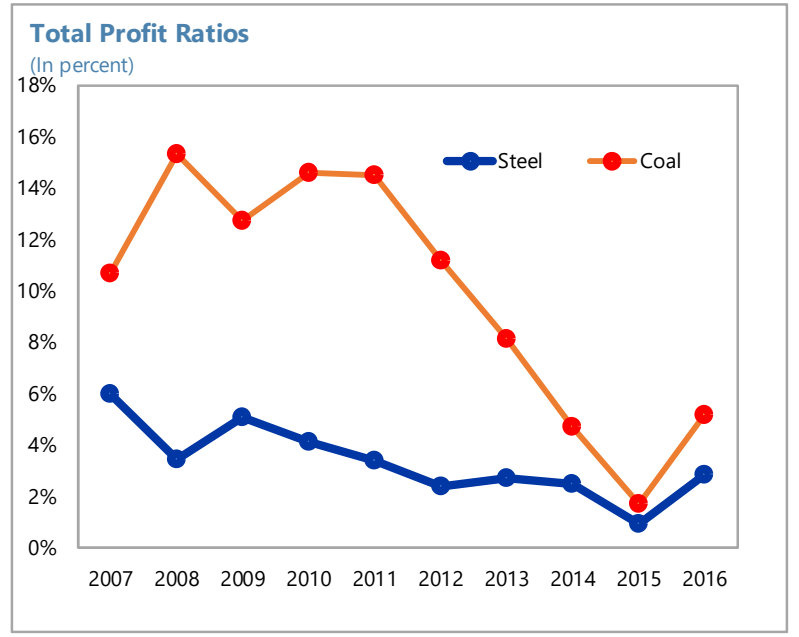
also raised concerns internationally. According to the data published by China's Ministry of Commerce, about half of the anti-dumping and anti-subsidy investigations against China in 2016 were related to steel (and China has been under more anti-dumping and anti-subsidy investigations than any other countries for twenty consecutive years). In the 2015 Hangzhou summit, the G20 Group noted that excess capacity in steel and other industries was a global issue. A Global Forum on Steel Excess Capacity was formally established in December 2016 by the G20 Group with a goal to find collective solutions, with each economy taking the necessary actions to foster a level playing field in the global steel industry.

6. Following the announcement of the SSSR in December 2015, China's State Council set targets for steel and coal capacity reduction by 45 million tons and 250 million tons receptively within the year (State Council 2016a and 2016b). The documents also announced that, within "three to five years", steel capacity would be reduced by 100-150 million tons (about 8-12 percent of the end-2015 capacity) and coal capacity by 1 billion tons (about 20 percent of the end-2015 capacity). The targets were set in net terms so any new capacity, presumably with higher efficiency, would require deeper cuts to the existing capacity. The State Council documents also required all coal producers to reduce the number of annual working days from 330 to 267 , temporarily cutting coal production capacity by an additional 16 percent.

7. Capacity reduction was also introduced in the context of the Chinese government's broad environmental protection effort. A series of severe pollution episodes, beginning with the January 2013 "Airpocalypse", forced the government to take tougher environmental measures. At the annual National People's Congress in March 2016, Premier Li Keqiang announced measures to cut coal consumption and vehicle emissions as well as punish "government officials who ignore environmental crimes." Emissions from Hebei, a province in Northern China with a large industrial sector that produces itself more steel than the United States, are a major source of regional pollution affecting Beijing. It is therefore not surprising that when the steel capacity reduction target was announced in 2016, Hebei alone accounted for more than a third of the planned annual reduction (Greenpeace 2017). 
8. According to published data, China is likely to achieve its capacity reduction goals well ahead of schedule. Steel capacity was curbed by 115 million tons in 2016-17, more than 75 percent of the 5-year target set for 2016-20. China also phased out the production of 140 million tons of steel made from scrap metal which led to a surge in scrap steel exports to 2.2 million tons in 2017 compared with just around 1,000 tons in 2016. China curbed its coal capacity by more than 290 million tons in 2016 and another 150 million tons in 2017, and reduced the number of coal mines from 10,800 in 2015 to about 7,000 at the end of 2017. With the significant capacity cuts, capacity utilization ratios and profitability improved markedly in both industries.
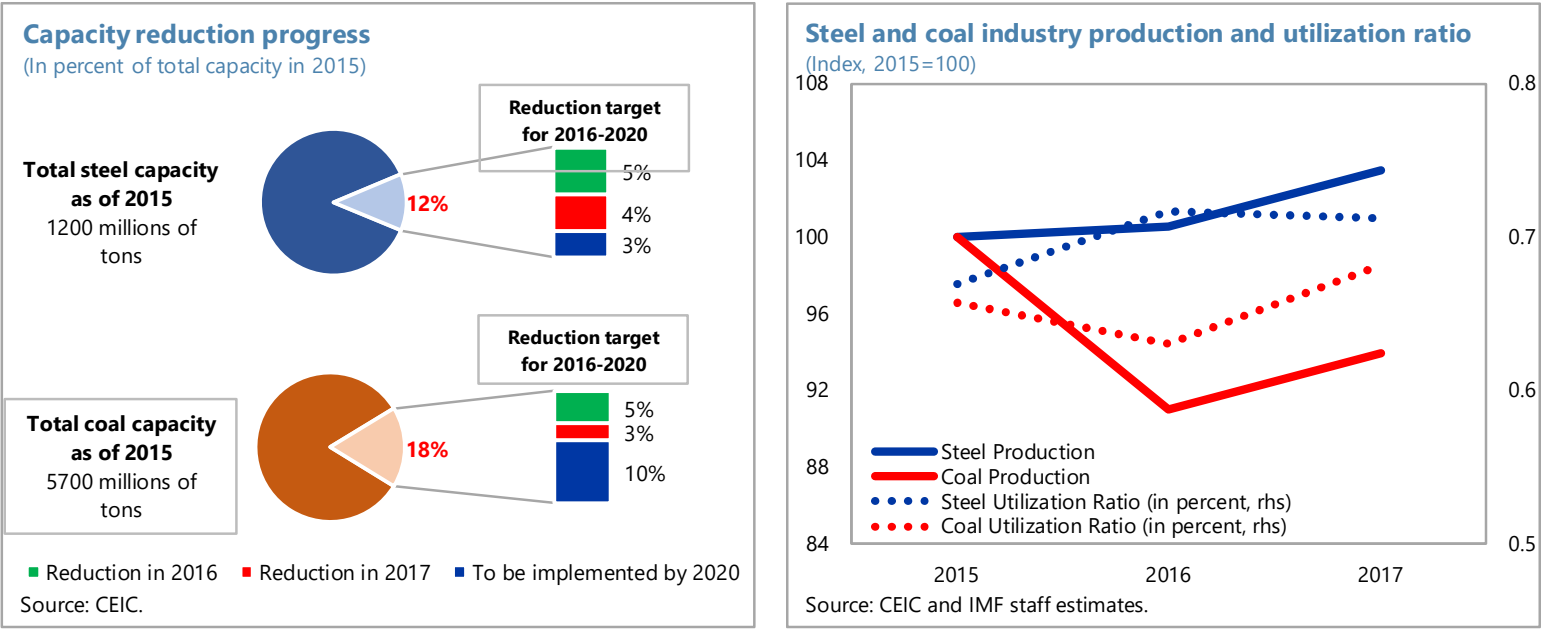

9. In this paper we quantify the contribution of capacity cuts in coal and steel to the significant turnaround of producer price inflation. China's producer price index (PPI) inflation, after being trapped in negative territory for 54 months, turned positive in September 2015 and has remained robust thus far. This has in turn led to improved corporate revenues and profits including in the steel and coal industries. Although the PPI reflation was broad-based, it is natural to draw the connection between the rising industrial prices, and capacity reduction efforts, which reduced competitive pressures in steel and coal production and led to higher prices of steel and coal, two important inputs for most, if not all, of the

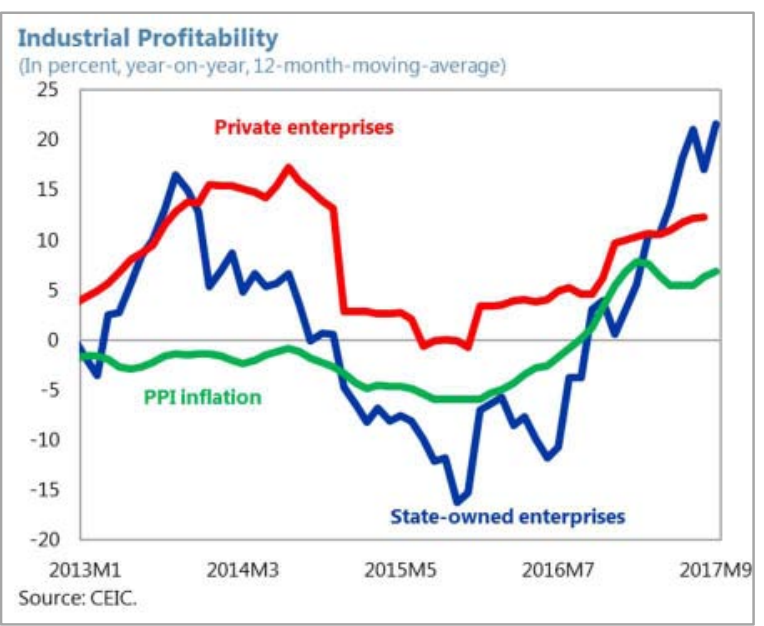
industrial sectors. Indeed, encouraged by the progress thus far, the government plans to expand capacity cuts to more industries including cement, electrolyzed aluminum, flat glass and coal-fired power plants. 
10. However, rising prices are not necessarily only due to tighter supply. Despite the reduced capacity, actual investment and production in metals processing and coal remains strong. Crude steel production, for instance, grew by 1.2 percent in 2016 and another 5.7 percent in 2017. The improvement in corporate profitability since 2015 has been more significant in the upstream industries than in the downstream industries, an indication that higher coal and steel prices may not have been fully transmitted to prices of other industrial products. Meanwhile, the growth momentum of the Chinese economy strengthened markedly after a brief period of moderation in mid-2015, thanks to the government's stimulus policies that boosted infrastructure spending, real estate activity and credit and likely resulted in a pickup in aggregate demand.

11. Our results indicate that the general recovery in aggregate demand, rather than capacity reduction, was likely a more important driver of the PPI reflation. While capacity reduction has certainly played a role in propping up producer prices in steel and coal, it does not explain the broad-based reflation that touched other upstream industries whose production is not directly linked to steel or coal. Moreover, profits and margins rose broadly, including in downstream sectors, which suggests an important role for demand. The main findings are:

- We find that demand factors explain around 60 percent of the change in PPI in the coal and steel industries.

- Capacity cuts account for $1 / 4$ to one third of the change in PPI in the coal and steel industries. $^{2}$

- For other upstream industries, demand factors more than explain the rise in PPI in industries chemical products (225 percent), non-ferrous metal extraction (121 percent), and nonferrous processing (123 percent) and up to 92, 97 and 70 percent in ferrous metal extraction, petroleum processing and petroleum extraction, respectively. ${ }^{3}$

- Allowing capacity cuts to have different impacts across steel and coal industries, we find that capacity reduction seems more important in the steel industry accounting for 42 percent of the change in PPI in 2016-17, while capacity cuts do not have a statistically significant impact in the coal industry.

\footnotetext{
${ }^{2}$ Regression residual account for the remaining portion.

${ }^{3}$ A number lager than 100 percent means that demand factors more than explain the change in producer prices in that sector.
} 


\section{EMpiricAl ANALYSES}

\section{A. Understanding Producer Prices in China}

12. China's PPI index currently consists of 76 percent intermediate goods and 24 percent final consumer goods. Volatility of prices follows a general upstreamdownstream ordering, with prices of mining and quarrying being the most volatile and prices of consumer goods the least. The PPI experienced a prolonged period of negative growth from 2012 to mid-2015, driven by declining prices of intermediate goods, while prices of final consumer goods remained stable.

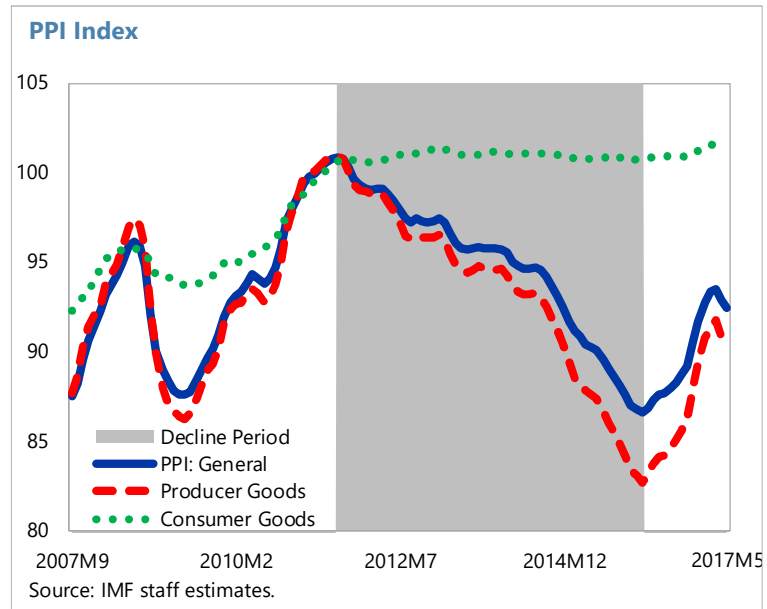

13. A decomposition of the PPI indicates that its dynamics are dominated by developments in upstream industries. Eight upstream industries (chemical products, coal, ferrous metal extraction, ferrous metal processing, nonferrous metal extraction, nonferrous metal processing, petroleum extraction, and petroleum processing) ${ }^{4}$ together accounted for more than 80 percent of the variance of overall PPI since 2013. Although the prices of these eight industries are highly correlated, these industries produce mostly inputs used in secondary and tertiary industries without much direct production linkages among themselves. Therefore, we can focus on the price dynamics of these eight industries, including coal and steel, which would allow us to keep the econometric analysis parsimonious while exploiting information contained in a large set of variables.

14. We first investigate the impact of capacity cuts in a panel setting, by comparing price movements of the targeted industries (steel and coal) to those of the other six upstream industries, while controlling for demand from downstream industries which may also drive price movements. We then move on to time-series analysis for coal and steel individually.

\footnotetext{
${ }^{4}$ Ferrous metal includes iron and steel. Nonferrous metals include aluminum, copper, and zinc.
} 

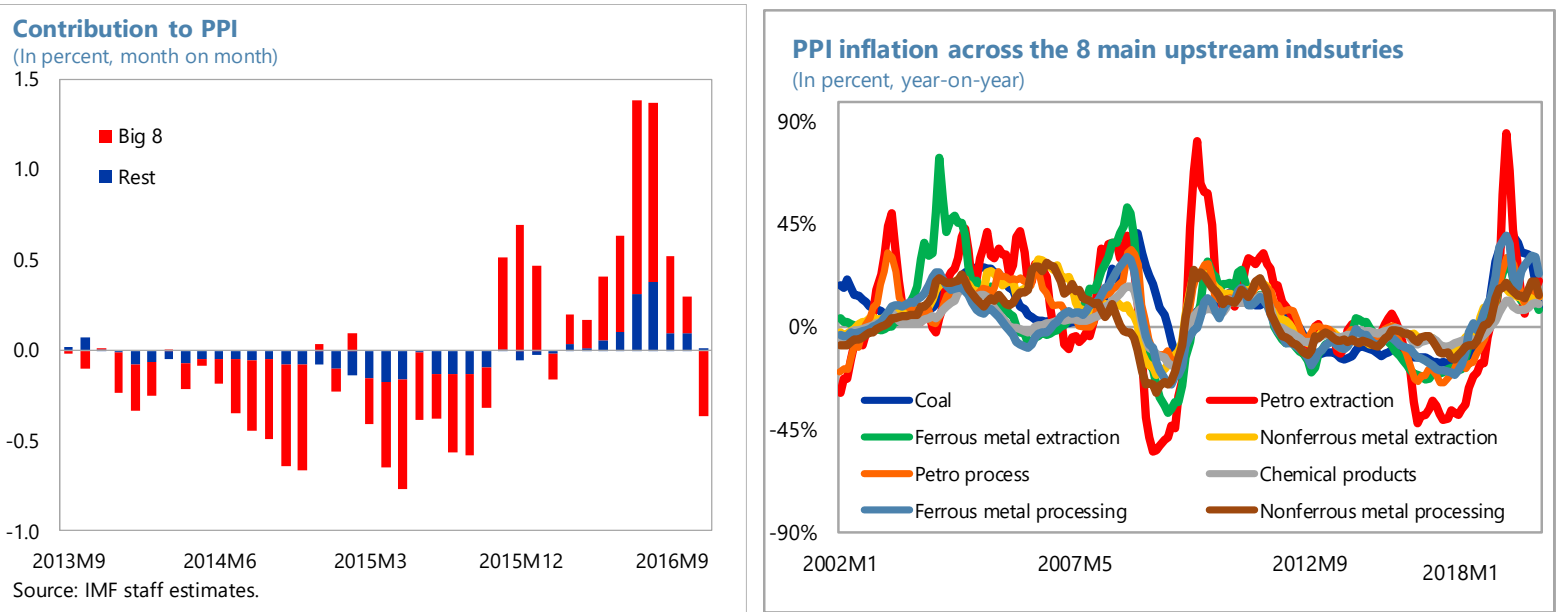

\section{B. Common Demand Factors}

15. To properly capture demand and yet remain parsimonious, we exploit a large number of demand variables that represent downstream demand, and extract common demand factors (see Appendix I for the list of variables). We use factor analysis techniques to extract common demand factors. The top three common factors together explain around 70 of variations of a set of 40 demand variables.

16. The three factors capture multiple dimensions of downstream demand. The charts below plot the three factors separately, and the three series that comove more closely with each factor. ${ }^{5}$ Factor 1 comoves most with changes in inventory of key downstream industries, general equipment, furniture and overall manufacturing product inventory. Factor 2 comoves most with manufacturing value added variables, like electric machinery and equipment and special equipment as well as real estate investment. Factor 3 comoves with auto-inventory, price of asphalt and electricity consumption. These factors capture well the strengthening of demand after mid-2015, as the government implemented stimulus measures including boosting infrastructure spending, credit expansion and housing market policies in response to the growth slowdown. The strong pickup in housing market activity, for instance, had a direct impact on the demand of construction materials including steel.

\footnotetext{
${ }^{5}$ The series are selected based on a ranking of largest R-squared when regressed on the factors.
} 

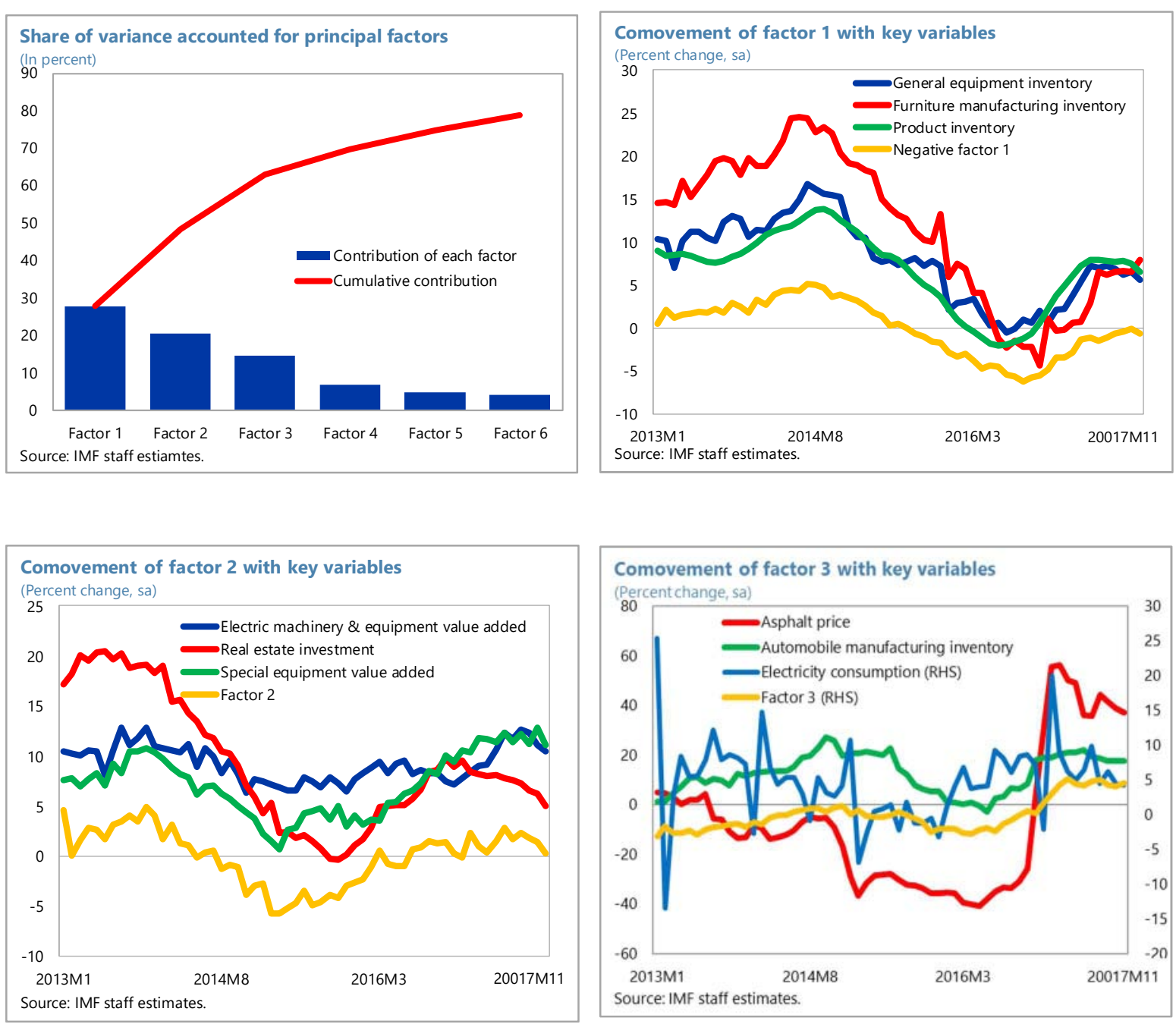

\section{Panel regression: pooling demand and supply factors across sectors}

17. Having estimated factors that capture demand conditions, we turn to a panel regression analysis of the drivers of PPI, where we evaluate whether capacity cuts in steel and coal, measured as the actual capacity reduction relative to end-2015 capacity, had a statistically significant impact on producer prices. ${ }^{6}$

18. The panel regression model is specified as follows.

$$
\Delta P P I_{i, t}=\beta X_{t}+\delta D_{i, t}+\varepsilon_{i, t}
$$

${ }^{6}$ As a robustness check, we also defined capacity cuts using industry-time dummies. Results are broadly unchanged from those presented in the text and are available upon request. 
where $\triangle P P I_{i, t}$ denotes the year-on-year growth rate of the PPI index for industry $i$ of the eight upstream industries at time $t$. On the right-hand side of the equation, $X_{t}$ is a vector of the three common factors extracted above, also including a common constant.

19. In the baseline specification, the variable that captures capacity reduction, $D_{i, t}$, is measured as the semi-annual reduction ${ }^{7}$ in capacity in percent of end-2015 capacity. $D_{i, t}$ only takes non-zero values after 2015, and only for the intervened industries of steel and coal. A positive $\delta$ indicates that the intervened industries indeed experienced faster price increases compared to the other industries, controlling for demand factors. Our sample includes monthly data from January 2012 to November 2017.

20. The point estimate of $\delta$ (at 0.09 ) is positive and significantly different from zero. (Table 1). Admittedly $\delta$ could conflate many forces that drive PPI growth in intervened industries other than capacity reduction, but data limitations prevent us from separating other supply-side factors from capacity measures at the industry level.

21. Capacity reduction efforts were indeed important in propping up steel and coal prices. For steel and coal, capacity reduction represents about 34 and 25 of the change in PPI in 2016-17, while demand factors represent 63 and 59 percent respectively, with the regression residuals accounting for the remaining. The PPI reflation in other upstream industries not subject to capacity reduction can also be explained by the common demand factors. For the other 6 industries that did not see capacity cuts, the common demand factor accounts for $70-$ 225 percent of the change in producer prices, meaning common demand factors are more than sufficient to account for the change in PPI, with the remaining accounted for by regression residuals.
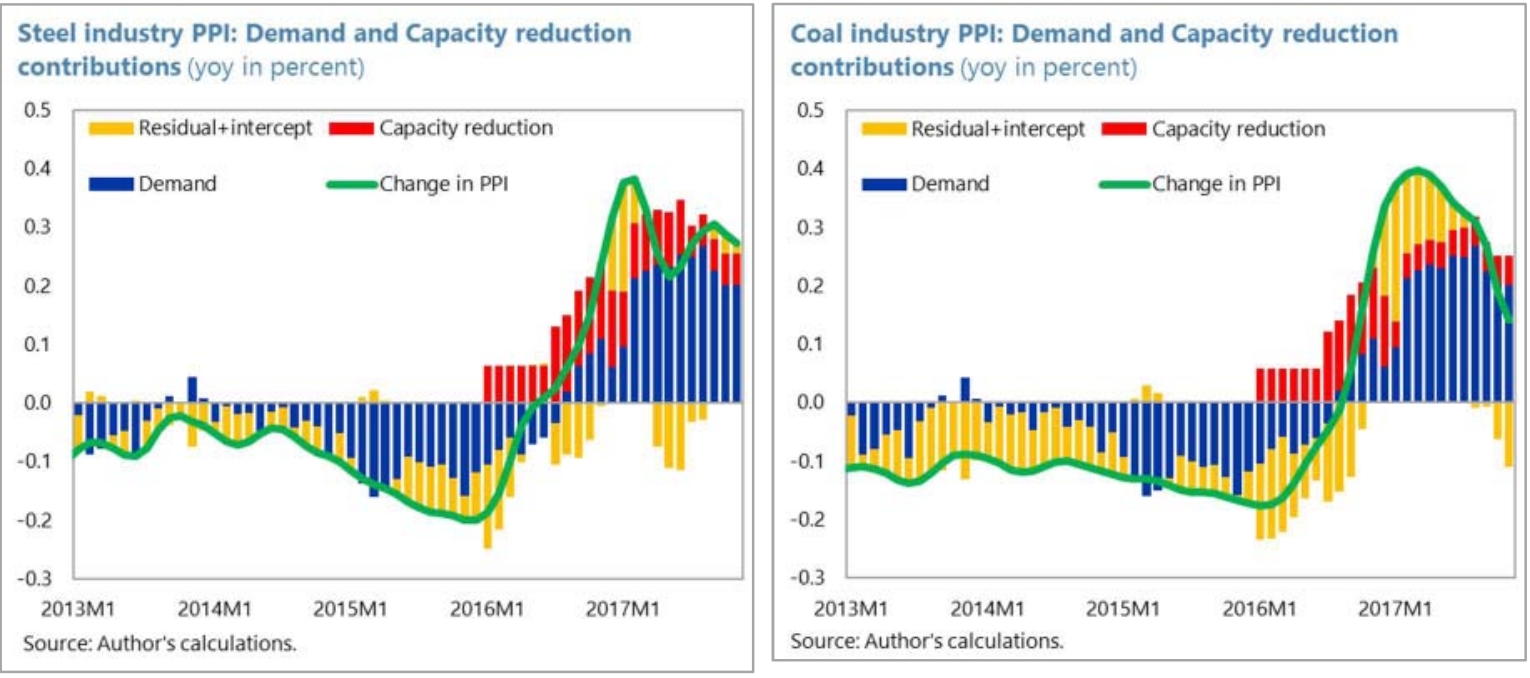

\footnotetext{
${ }^{7}$ We use semi-annual, rather than monthly, capacity reduction because of data availability. Still, we note that capacity reduction efforts have been applied quite uniformly at the semi-annual frequency.
} 
22. To give a more intuitive interpretation of the effect of capacity reductions, we perform a difference-in-difference exercise. Table 2 shows the average year-on-year growth of industry-level PPI (the LHS variable, after controlling for demand factors we extracted conditional on whether the capacity measures are in place (baseline $=$ before treatment, follow-up $=$ after treatment) and whether the industry $i$ is affected (control $=$ not affected by capacity reduction, treated $=$ affected). The results suggest that the coal and steel industries enjoyed much higher PPI inflation (11 percent higher) once the policy was in place, compared to industries were not intervened.

\section{Time-Series Analysis: Allowing Sector-Specific Demand and Supply Effects}

23. The above results indicate that, although capacity cuts did lead to a faster recovery of the coal and steel prices, the broad PPI reflation since mid-2015 can be mostly explained by common demand factors. However, the panel regression pools the effects across coal and steel industries, ignoring that there may be differences in the effectiveness of capacity reduction efforts across them. In this section, we use a time series analysis to examine the drivers of coal and steel prices, separately.

24. We allow coal and steel to have heterogeneous elasticities to the same three common demand factors explored previously. The model is specified as follows.

$$
\Delta Y_{i, t}=\beta_{i} X_{t}+\delta_{i} D_{i, t}+\varepsilon_{i, t}
$$

where $\Delta Y_{i, t}$ is year-on-year PPI inflation for sector $i$, where $i=\{$ coal, steel $\}, X_{t}$ is the vector of the three principal factors identified in the previous exercise, and the capacity cut variable $D_{i, t}$ measures semi-annual capacity cuts in percent of end-2015 capacity. $\delta_{i}$ captures the effect of capacity reduction on prices in industry $i$, and is therefore not pooled. Our sample includes monthly data from March 2012 to December 2017 for coal and from August 2012 to December 2017 for steel.

25. We find that the individual sector regressions attribute an important role to capacity reduction efforts in steel but not for coal:

- For the steel industry, we find that demand, still explains a substantial fraction of steel price movements (58 percent), while capacity cuts account for 42 percent, larger than in the panel regression.

- However, for the coal industry we find that demand factors account for the full shift in PPI inflation in the sector, with capacity reduction becoming insignificant. 

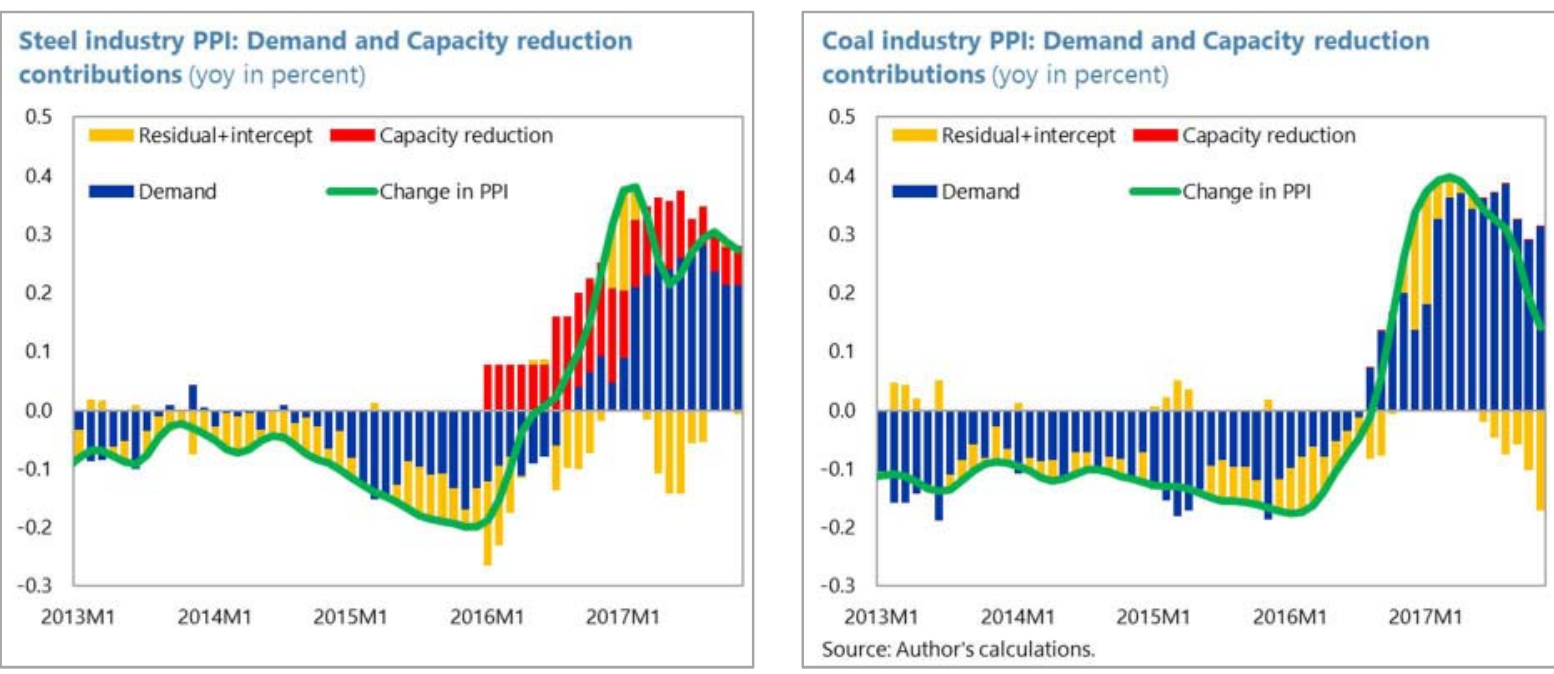

\section{Conclusions}

26. We find that the strengthening of downstream demand played a major role in the broad-based PPI reflation in China since mid-2015. For the coal and steel industries, capacity cuts also played a role in shoring up prices. Demand factors likely reflect policies implemented in 2015-16 to boost infrastructure investment and housing sector activities. Destocking in the residential housing market, for instance, contributed to a resurgence in housing prices and sales particularly in China's smaller cities since 2015, until the government significantly tightened housing market policies to contain the house price bubble (Ding et al 2017). 2016 also saw a large increase in public sector infrastructure investment. Finally, tax cuts may have also played a role in boosting demand in downstream industries that supported upstream prices, such as the tax cut on vehicle purchases and a reduction in business taxes. Thus, the full package of stimulus policies seems to have been important.

27. In theory, capacity reduction efforts can be welfare-improving if offsetting existing market failures. During the 2012-15 deflation episode, coal and steel industries witnessed steady production increases despite prolonged loss-making. It is possible that distortions prevented firms from lowering production or exiting when their selling price was consistently below average cost. For example, local governments may have incentives to provide financial support to steel mills that account for a significant share of local employment, investment, and tax revenue, even if the firms' long run solvency could be questionable. Capacity reduction may facilitate the exit of such insolvent (and low-capacity) firms. Suboptimally excessive production also leads to a negative externality on the environment through air pollution.

28. However, higher prices are not a sufficient condition for assessing whether capacity reduction is welfare improving. First, pervasive loss-making (price below average cost) is not necessarily a signal of market failures. As shown by Dixit and Pindyck (1994), loss-making firms may optimally choose to stay in the market when large upfront investments are not 
easily reversible, as it would be too costly to re-enter if prices recover. Second, capacity reduction could exacerbate resource misallocation if it falls disproportionately on private firms. Third, rising steel and coal prices push up costs of downstream industries, including electricity generation, real estate, and manufacturing, and could just be a transfer without net positive welfare impacts. In this regard, the strong pickup in aggregate demand was important to mitigate the impact of surging steel and coal prices on the downstream industries. Without it, this would have hurt industries that use coal and steel as inputs, and would have been a transfer of resources to those two industries. Fortunately, strong demand allowed the downstream industries (and other upstream industries) to also raise their prices.

29. A fuller cost-benefit analysis is outside of the scope of this paper, but would be desirable if capacity cuts are to be expanded to other industries. Supporting prices is a necessary condition for capacity cuts to have an overall positive welfare impact. But it is not sufficient, as capacity cuts alone can be a transfer, both within the intervened industries (from targeted firms to unaffected ones) and between intervened and non-intervened industries. 


\section{References}

BP, 2017. Statistical Review of World Energy 2017. British Petroleum, London.

Dixit, A. K. and R. S. Pindyck, 1994, “Investment under uncertainty,” Princeton university press.

Ding, D., Huang, X., Jin, T. and W. Lam, 2017, “Assessing China's Residential Real Estate Market," IMF Working Paper No. 17/248.

EIU, 2017. China's Supply-Side Structural Reforms: Progress and Outlook. Intelligence Unit, the Economist.

Fan, R., 2016, “China's Excess Capacity: Drivers and Implications," Law Offices of Stewart and Stewart.

Haley, U.C.V. and G.T. Haley, 2013. Subsidies to Chinese Industry: State Capitalism, Business Strategy and Trade Policy. Oxford University Press, Oxford.

State Council 2016a, "The Opinion on Resolving Overcapacity and Difficulties in the Steel Industry," Guofa 2016-6.

State Council 2016b, "The Opinion on Resolving Overcapacity and Difficulties in the Steel Industry," Guofa 2016-7. 
Appendix I. List of Downstream Demand Variables Used to Extract Common Factors ${ }^{8}$

Aggregate variables:

1. Credit growth

2. Value-added of industrial sector

3. Electricity consumption

4. Railroad traffic

Real estate sector:

1. Vacant floor space/sales of floor space ratio

2. Fixed asset investment

3. Floor space under construction

Infrastructure:

1. Fixed asset investment

2. Number of government projects

3. Local government loan value

Industrial production of:

1. Rubber products

2. Furniture

3. General equipment

4. Machinery

5. Automobile

Inventory stock of:

1. Rubber products

2. Furniture

3. General equipment

4. Machinery

5. Automobile

Inventory/sales ratios

1. Steel billet inventory/steel billet sales

2. Automobile inventory/automobile sales

\footnotetext{
${ }^{8}$ All variables are either ratios or in year-on-year growth rates.
} 
Appendix II. Regression Tables

Table 1: Panel regression of changes in PPI assuming homogeneous coefficients (dependent variable is changes in PPI in the 8 upstream industries)

\begin{tabular}{lc} 
& $(1)$ \\
\hline Factor 1 & $0.01^{\star * \star}$ \\
Factor 2 & $(7.04)$ \\
& $0.02^{\star * \star}$ \\
Factor 3 & $(16.51)$ \\
& $-0.04^{\star \star *}$ \\
Capacity reduction & $(-21.02)$ \\
& $3.55^{\star \star *}$ \\
Constant & $(5.07)$ \\
& $-0.03^{\star \star \star}$ \\
Observations & $(-6.55)$ \\
R-squared & 472 \\
\hline
\end{tabular}

Source: author's estimates.

$T$-statistics in parentheses. ${ }^{*} p<0.05,{ }^{* *} p<0.01,{ }^{* *} p<0.001$.

Table 2: Difference-in-difference decomposition of changes in PPI (dependent variable is changes in PPI in the 8 upstream industries)

\begin{tabular}{lcccc}
\hline & Mean PPI & Std. Error & $t$ & $\mathrm{P}>|\mathrm{t}|$ \\
\hline Before capacity cuts & & & & \\
$\quad$ Control & -0.02 & 0.01 & -1.62 & 0.11 \\
Treated & -0.04 & 0.01 & -4.56 & 0.00 \\
$\quad$ Difference & -0.03 & 0.01 & -3.83 & 0.00 \\
After capacity cuts & & & & \\
Control & -0.04 & 0.01 & -2.63 & 0.01 \\
Treated & 0.05 & 0.02 & 2.41 & 0.02 \\
$\quad$ Difference & 0.09 & 0.02 & 5.07 & 0.00 \\
Difference in difference & 0.11 & 0.02 & 6.12 & 0.00 \\
\hline
\end{tabular}

Source: author's estimates.

$T$-statistics in parentheses. ${ }^{*} p<0.05,{ }^{* *} p<0.01,{ }^{* *} p<0.001$. 
Table 3: Industry-specific estimates for coal and steel

(dependent variable is industry-specific PPI changes)

\begin{tabular}{lcc}
\hline Dependent variable: & Coal & Steel \\
\hline Factor 1 & $0.02^{\star \star \star}$ & 0.01 \\
& $(4.5)$ & $(1.1)$ \\
Factor 2 & $0.02^{\star \star \star}$ & $0.02^{\star \star \star}$ \\
& $(6.6)$ & $(7.0)$ \\
Factor 3 & $-0.06^{\star \star \star}$ & $-0.04^{\star \star \star}$ \\
& $(-15.8)$ & $(-9.7)$ \\
Capacity reduction & -0.13 & $4.3^{\star \star}$ \\
& $(-0.1)$ & $(2.7)$ \\
Constant & -0.02 & $-0.04^{\star}$ \\
& $(-1.1)$ & $(-2.3)$ \\
Observations & 59 & 59 \\
R-squared & 0.88 & 0.87 \\
\hline Source Author & &
\end{tabular}

Source: Author's estimates.

$T$-statistics in parentheses. ${ }^{*} p<0.05,{ }^{* *} p<0.01,{ }^{* * *} p<0.001$. 